\title{
Comentario
}

\section{Cuando lo reprimido vuelve: lo subversivo de la subjetividad femenina}

\author{
Ursula Hauser ${ }^{1}$
}

\section{Introducción}

Primero que nada quiero resaltar el valor del amplio y profundo trabajo de la profesora Roxana Hidalgo, dado que el tema de la fuerza sexual y agresiva de la mujer, sobretodo la última, sigue siendo uno de los talones de Aquiles dentro del psicoanálisis, y quizás en las ciencias sociales en general. Como menciona la profesora Hidalgo, a pesar de los múltiples trabajos sobre género, psicoanálisis y feminismo a escala nacional e internacional, y en muchos programas de maestrías de estudios de la mujer, parece permanecer una resistencia para profundizar en este tema, de manera que el "sujeto feminista subversivo" (Butler, 1990) sigue esperando para su profundización. Por lo tanto, el presente trabajo significa la continuación de la búsqueda por responder a interrogantes que nos hemos planteado ya sea en Europa, en los Estados Unidos o en Latinoamerica: ¿Cómo se manifiesta el deseo sexual femenino? ¿Cuáles son las expresiones agresivas femeninas? ¿Será "natural" la escogencia heterosexual de la mujer, o es una imposición cultural? ¿Qué significa científicamente el termino "mujer"? ¿Cuál es el límite entre las construcciones biologistas y socioculturales? ¿Cómo se encuentra el camino de subvertir los prejuicios históricos?, etc. ${ }^{2}$ Estimulada por el trabajo de Roxana Hidalgo me gustaría profundizar en torno a) al desarrollo de la sexualidad (heterosexual y homosexual-lésbica) femenina; b) a los aportes y la lucha de mujeres psicoanalistas dentro del movimiento psicoanalítico a lo largo de cien años de historia del psicoanálisis; c) la ampliación del concepto de "masoquismo femenino" y "narcisismo"; d) a la experiencia clínica en Costa Rica y la comprensión que permite de las influencias del poder dominante del Estado patriarcal y de la Iglesia católica en el desarrollo de la identidad feminina (y masculina); e) a algunas reflexiones etno-psicoanalíticas.

\section{E1 desarrollo de la sexualidad (hetero y homosexualidad) femenina}

Ya que la profesora Hidalgo nos introduce a la mitología griega que sirvió a Freud en su concepto del "drama edípico", como núcleo constitutivo para la construcción de la identidad adulta, propongo en lo siguiente y para complementar el trabajo de la profesora Hidalgo, algunos aspectos para analizar la figura de Antígona.

Para comenzar con esta discusión, quiero recomendar la obra de Judith Butler (2000): Antigone's claim. Kinship between life and death, donde la autora pone en el centro de sus reflexiones a Antígona como un ejemplo de un "sujeto feminista subversivo". No es por casualidad que muchos

\footnotetext{
${ }^{1}$ Dedico este breve texto a Luisa González, mujer rebelde, luchadora, maestra y una de las iniciadoras del proyecto de la universidad obrera en los años cuarenta, junto con la participación de Adela Ferreto, Carmen Lyra, Estela Peralta, Emilia Prieto, Carlos Luis Sáenz. Igualmente está presente en esta contribución Goldy Parin-Matthey, mi psicoanalista, internacionalista, quien desde la guerra civil en España hasta su muerte integró su saber psicoanalítico con su espíritu de luchadora social. ¡Gracias Luisa, gracias Goldy, por ensenarños que a pesar de las derrotas siempre quedan la sonrisa y el amor, estímulos para seguir luchando!

${ }^{2}$ En 1989 fundamos en Costa Rica la Asociación de Psicoanálisis y Psicologia Social (ASPAS), y el tema de género igual que el tema de los derechos humanos son nuestras inquietudes centrales. Nuestro interés es el debate, la discusión y la revisión de estructuras de poder inconsciente en las subjetividades de ambos géneros, también en el funcionamiento de instituciones y a nivel socio-cultural y siguen siendo aspectos de análisis centrales.
} 
grupos feministas se sirven de su nombre para simbolizar su lucha. Antígona, la heroína de la Edad Antigua incorpora dentro de una larga tradición del pensamiento occidental un ejemplo magistral de una actitud anti-autoritaria. La psicoanalista francesa Luce Irigaray reconoce en Antígona el principio de la resistencia femenina en contra de la autoridad estatal. Antes, para Hegel, Antígona representaba la defensora del derecho familiar divino en contra de la ley humana, masculina. Butler contradice a esta tradición. Su Antígona no es la figura galionica de la resistencia feminista, sino "una figura en crisis", un sujeto subversivo; pero ¿qué quiere decir esto? En la tragedia de Sófocles, Antígona entierra a su hermano en contra de la ley estatal y paga esta transgresión con su vida. Ella defiende, -desde la interpretación de Hegel- el derecho familiar en contra de la lealtad con el estado. Butler indica que se suele olvidar que Antígona es la hija de Edipo y por lo tanto se encuentra atada dentro de relaciones incestuosas, las cuales cuestionan la noción de familia "natural", sobre todo desde el psicoanálisis. Dentro de la interpretación de Hegel y después igualmente en Lacan, este modelo de familia "natural" es una condición que no se problematiza. Butler tiene el interés de demostrar que el tabú del incesto como fundamento de este modelo familiar se basa sobre una prohibición de la homosexualidad, porque está condicionada desde la noción natural del deseo sexual como heterosexual.

El psicoanálisis igual que el estructuralismo dan por entendido el (no permitido) deseo entre padre e hija o madre e hijo y declaran el tabú del incesto como principio fundamental de los lazos familiares. Esta "matriz" cultural de la heterosexualidad y la consecuente dimensión de un tal orden familiar queda sin reflexionar y con Butler aún peor, dado que actúa como ley que no es reflexionable o discutible por su aparente naturalidad.

Butler nos demuestra una Antígona dentro de la problemática ambivalente de "lo marginado" y "lo prohibido". Por el hecho de que aparece en la mitología griega como hija de Edipo, pero también aparece como su hermana, disuelve su identidad dentro del orden familiar. Representando a aquellas/os seres humanas/os que están excluidas/os de un sistema que es para ellas/os de significación existencial, Antígona simboliza la posición entre ser y no existir, entre vida y muerte. La resistencia de Antígona en contra de la autoridad estatal por lo tanto no puede ser representativa, no es un principio en general, porque no es posible definir su identidad de forma incuestionable. Para Butler, ella es una figura "entre espacios" y esta percepción en sí puede contener energía subversiva. Siguiendo las huellas de Antígona, Butler escribe en contra de ideas dogmáticas de genero, sexualidad y diferentes formas de vida que no permiten una reflexión crítica.

Podríamos pensar que esta interpretación permite simbolizar la figura de Antígona como representante de aquellas/os que se ubican en la periferia del orden estatal, además puede incorporar un nuevo paradigma para "un sujeto en el centro" y entender lo político desde la periferia, desde posiciones "híbridas". Butler (2000) discute las nuevas perspectivas desde la idea del sujeto en el centro. Ella confronta a Freud con Foucault en el cuestionamiento de si la teoría psicoanalítica se presta para entender el reflejo intra-psíquico de estructuras de poder discursivas e institucionales. Si esto fuera cierto, entonces se podrá demostrar cuáles son los mecanismos responsables de una lógica dominante que expulsa lo diferente no solamente dentro de estructuras externas, sino también en el ámbito interno de la psique. Por lo tanto Butler demuestra que la construcción de una identidad feminina o masculina de acuerdo con Freud y su teoría psicoanalítica condiciona la prohibición del deseo sexual hacia el mismo género. Los propios deseos homosexuales y emociones concomitantes, se tienen que someter bajo la prohibición de recordarlos y al mismo tiempo olvidarlos, sin haber hecho un duelo por ellos. Esta "melancolía" como expresión y resultado de una homosexualidad prohibida nos lleva, de acuerdo con Butler, al centro de la psique heterosexual "normal" y será una de sus condiciones funcionales.

Siguiendo sus reflexiones acerca de una Antígona ambivalente nos brinda la oportunidad de entender no solamente aquellos sujetos que tienen un estatus marginalizado como seres humanos femeninos, poscoloniales y homosexuales. Más allá de esto explica expulsiones internas, que se dan en cada proceso de construcción de la identidad. Este continuo "fracaso" de "una identidad cumplida" se transforma hacia una forma de condición universal (y su límite también) de la formación del sujeto. Esto tiene consecuencias éticas. Exige de "los sujetos en el centro" una actitud abierta para la crítica hacia normas de la constitución de la propia identidad y humildad hacia las/los otros sujetos. Butler integra el análisis de la identidad híbrida de Antígona con el análisis de sus actos en contra de la autoridad estatal. Solamente así pueden tomar un efecto político sus condiciones subversivas.

Antígona desarrolla a pesar de su posición periférica una capacidad de actuar políticamente, mediante la apropiación del idioma del poder estatal y dirigirla en contra de éste. Públicamente ella 
insiste en su posición indefinible como hija, hermana y amante y conserva así su conciencia de su identidad "híbrida". También Antígona habla -como el rey- en forma de un "yo" y reclama una soberanía por sus actos, a pesar de que el análisis de Butler demuestra que esta soberanía es ficticia. Lo subversivo del acto de Antígona por lo tanto es que ella entra en el discurso público desde su posición ambivalente y desarrolla "poder" como sujeto "híbrido".

Lo subversivo siempre se mueve en un límite entre reacción y ficción y opera en el medio precario de la sumisión y la utopía. Paralelo con este movimiento se corre el riesgo de autoequivocación y una sobre-evaluación de los efectos de la propia resistencia. También se puede subvalorar cómo los propios actos pueden legitimizar condiciones de poder y de opresión.

Después de estas reflexiones desde el feminismo filosófico de Judith Butler quiero resaltar, tal como lo apunta Roxana Hidalgo, la necesaria reinterpretación del drama edípico para las niñas mujeres (Hauser, 2000b.), una tarea que Melanie Klein empezó a elaborar como pionera del psicoanálisis desde la observación directa con niñas/os. El primer objeto de amor fue para ella (igual que para el varón) la madre, la relación con el padre u otra tercera persona significativa suele establecerse más tarde. La renuncia del lugar preferido en el pecho de la madre causa un conflicto en la frágil autonomía y en el narcicismo de la niña y depende mucho de la autoestima de la madre como mujer -aparte de la norma cultural-, de cómo se resuelve esta problemática en función de la construcción de la identidad femenina. De cualquier manera será esta etapa el inicio de los sentimientos profundos de ambivalencia hacia la madre, donde se entremezclan las emociones de amor y odio. Hidalgo hace un amplio reconocimiento de psicoanalistas como Melanie Klein (1932) y Margareth Mahler (1952) quienes crítican la teoría de Freud en esta punto. El enfoque pre-edípico amplía la problemática de la relacion primaria entre madre y niña, apuntando hacia los sentimientos fuertes de odio, envidia y ambivalencia de la niña hacía la omnipotente figura de la madre, que significan los conflictos basicos en los procesos de "separación" e "individuación" y para la constitución de la femenidad.

\section{Aportes y lucha de mujeres psicoanalistas dentro del movimiento psicoanalítico}

Roxana Hidalgo nombra muchas colegas así como los aportes valiosos y críticos que han hecho. Al respecto me parece importante complementar la discusión teórica con algunos hechos dentro de la história del psicoanálisis, que pueden demostrar las consecuencias sociales e institucionales de la "rebeldía".

Las críticas hacia la teoría del "padre Freud" siempre encontraron mucha resistencia y hasta expulsión del movimiento psicoanalítico, una vez que se institucionalizó como sociedad internacional (International Psychoanalytical Association, IPA). Las estructuras de poder patriarcal implícito fueron desde el inicio rígidas, supuestamente para "salvar el psicoanálisis" (Fallend, 1988; Reichmayr, 1990). De esta manera no solamente fue excluida Melanie Klein, sino también Wilhelm Reich (Jacoby, 1983), éste por su militancia dentro del partido comunista en los años 30. Más adelante, en el contexto de los movimientos estudiantiles marxistas en Europa y en la lucha contra las dictaduras en América Latina, se formó en el año 1969 el movimiento "plataforma internacional", donde la izquierda dentro del psicoanálisis se separó colectivamente de la IPA por razones ideológicas (Carrillo, 2000; Modena, 2000). Entre muchas colegas resaltó Marie Langer, psicoanalista austriaca quien vivió y trabajó desde su exilio del nazismo (y después del terrorismo de Estado en Argentina) en Uruguay, Argentina y México. Ella es un ejemplo de pensadora psicoanalítica marxista que no escapó de la ideología patriarcal implícita en la noción de la realización de la sexualidad de la mujer a traves de la maternidad (1951). Mucho más tarde, criticada por nosotras, la generación de los 60 , ella cambió sus ideas alrededor de la sexualidad femenina. Difícilmente logramos como psicoanalistas feministas tener voz y voto, ni en las instituciones académicas estatales y tampoco en las organizaciones de izquierda. Similares dificultades existen hasta hoy entre grupos de feministas quienes rechazan globalmente al psicoanálisis. Creando espacios autónomos al margen de las instituciones seguimos buscando como ligar la teoría psicoanalítica con la práctica feminista.

Ejemplos de mi propia experiencia es el grupo que mujeres psicoanalistas en formación crearon dentro de "Plataforma Internacional": el grupo Merde. Este grupo buscaba analizar criticamente las estructuras de poder dentro de "Plataforma"; además formamos dentro del PSZ 
(Seminario Psicoanalítico de Zurich) un grupo de psicoanalistas mujeres para supervisar los procesos transferenciales específicos entre mujer-terapeuta y mujer-paciente.

\section{Ampliar el concepto de masoquismo femenino y narcisismo}

Siguiendo la mención que Hidalgo hace del tema del "masoquísmo femenino" como concepto sobre la sexualidad femenina dentro de la teoría psicoanalítica, pienso que este merece una revisión más amplia, dado que justamente la problemática del desarrollo pulsional (sexual y agresivo) de la mujer está en cuestión.

Ese concepto es responsable de legitimar mucho sufrimiento de mujeres quienes consideran "natural" su sufrimiento. Eros se reemplaza por Tanatos porque no se interpretó este teorema en su contexto histórico, ideológico y sociocultural. Feliz el Estado patriarcal igual que la Iglesia católica (también la protestante), de poder utilizar este concepto para seguir dominando la fuerza pulsional de las mujeres. Si no se reflexiona esta teoría sobre su base económica, en el contexto de un análisis crítico de la función de la mujer dentro de la distribución de roles en la familia y considerando la maternidad como eje central de la sexualidad femenina, por supuesto se biologiza lo que es en efecto una consecuencia del desarrollo histórico social de las relaciones entre los géneros (Engels, 1880), y de cómo una sociedad específica organiza su reproducción en las diferentes instituciones (familia, escuela, iglesia, etc.).

¿Por qué se mantiene con tanta fuerza esta teoría del "masoquismo femenino", si desde hace más de 100 años se analiza el funcionamiento de la familia como "célula del estado burgués" (Engels, 1979), a costa del trabajo gratuito de las mujeres y de su derecho de construir su identidad sexual más libremente? Parece ser de tanta importancia para el estatus quo, que se ha internalizado también en las filas de la izquierda. Es uno de los mitos más resistentes también dentro de la IPA y de instituciones psicoanalíticas, donde las voces críticas de mujeres rápidamente suelen ser interpretadas como "envidia del pene" o reacciones desde el lugar de la "castración".

Igualmente se utilizó el concepto freudiano del "narcicismo femenino acentuado" como impedimiento para entrar críticamente en el discurso oficial de las instituciones psicoanalíticas. Con razón se desarrolló un rechazo por parte de organizaciones feministas en contra del psicoanálisis; lamentablemente sin entrar en el debate y profundizar la crítica, para poder rescatar los aportes importantes del psicoanálisis.

\section{Aportes desde la experiencia clínica en Costa Rica}

Sería muy importante poder enriquecer el trabajo de la profesora Hidalgo con "casuística" de la experiencia clínica, para demostrar de que forma estos conceptos como fenómenos sociales siguen vigentes en Costa Rica. No es posible en este contexto, pero quizás se impulse un foro más amplio que permita seguir esta discusión. Solamente quiero nombrar las manifestaciones más conocidas de la represión sobre la fuerza sexual y sobretodo agresiva de las mujeres costarricenses, de diferentes clases sociales.

Dado que la educación está estrechamente ligada a los postulados de la Iglesia católica, el desarrollo psico-sexual de las niñas sufre un específico "destino de represión": en la mayor parte de las pacientes mujeres encuentro fantasías de su cuerpo como sucio, malo, pecador, malhecho, feo, etc. La menstruación está concebida como "enfermedad", cubierta con sentimientos de vergüenza y pena. La sangre será testigo de algún pecado, crimen y los dolores consecuentes son aceptados como naturales y en la fantasía inconsciente como castigo. "El crimen" casi siempre se descubre en forma de fantasías sexuales o de odio en contra de una persona amada. La masturbación suele ser tan reprimida, que muchas mujeres piensan que nunca se han tocado sus genitales, menos con placer (Hauser, 1991). El "complejo de inferioridad y suciedad" de las mujeres se asemeja a la problemática que el etnopsiquiatra Frantz Fanon (1952) encontró como "complejo de negritud" y que es responsable de la sumisión de la población negra bajo el dominio de los blancos desde su dinámica intra-psíquica. Es esa misma búsqueda por encontrar respuestas para actitudes de sumisión que aparecen como "masoquistas" y que pueden ser comprendidos desde la sociología como fenómenos de alienación. Los aportes de Parin et. al. (1963), los fundadores del 
etnopsicoanálisis, son importantes en este contexto, especialmente sus estudios sobre los mecanismos inconscientes de identificación con el "agresor" y los mecanismos de adaptación inconsciente.

Cuando se libera esta energía reprimida durante los procesos psicoterapéuticos, se suele presentar otro conflicto, ahora en la realidad social, dado que muchas veces el entorno familiar y social reacciona con rechazo a la nueva actitud de las mujeres. ¿Será este el precio por pagar cuando se rompen las cadenas de cientos de años de esclavitud y sumisión? Las ganancias secundarias de las neurosis igual que las psicosomatizaciones en las mujeres son seductoras, porque prometen el premio de la conformidad, a costo del conflicto intra-psíquico. Freud dice que el objetivo de la terapia será transformar la neurosis privada en la conciencia del malestar (miseria) social.

\section{Reflexiones etno-psicoanalíticas}

En la lectura del trabajo me hicieron falta algunas reflexiones subjetivas de la profesora Hidalgo al respecto del tema, dado que yo sé que la colega tiene una experiencia muy amplia en la investigación y seguramente también en su vida personal y profesional. Sería de mucho valor que ella una sus conocimientos teóricos con reflexiones desde su experiencia práctica (ver Chacón e Hidalgo, 2000).

La lucha de mujeres científicas en el ambiente académico suele ser dura, dado que muchas veces son invisibilizadas o discriminadas en las instituciones tradicionales. Pocas han escrito sobre sus experiencias. ¿Será este hecho una afirmación de lo que nos dice el texto de la profesora Hidalgo? Casi aparece encubierto el hecho de que las transformaciones históricas nunca vienen "naturalmente", sino que son consecuencia de las múltiples luchas de poblaciones oprimidas y marginalizadas (lucha de clases, de etnias, de mujeres, de homosexuales, de grupos de personas con discapacidades, etc.). Este punto toca la implícita posición ideológica. ¿Quiénes dominan el desarrollo histórico?, ¿En interés de quiénes? ¿Para quiénes? ¿Y cómo se logran cambios en el discurso y en la política dominante?

Por otro lado me irritó productivamente el concepto de la "otredad" aplicado a lo femenino y brevemente quiero compartir mis reflexiones. Para el etnopsicoanálisis la dinámica entre lo propio y lo ajeno, lo conocido y lo diferente es un punto central para estudiar, sobre todo en ambientes culturales de diferentes poblaciones. La reflexión empieza en el etnocentrismo, egoísmo, "yo" como punto de referencia igual como la/el bebé en su estado narcisista cuando se piensa el centro del mundo. Sin duda también utilizamos este concepto para "lo extraño dentro de mí mismo", en referencia al inconsciente y la dinámica intra-psíquica, sobretodo en relación con los impulsos sexuales y agresivos, que son sometidos a diferentes procesos de represión durante la socialización. Sigo con la duda sobre la validez de utilizar el concepto de "otredad" para la femenidad, pero me sirvió para recordar la necesidad de reflexionar alrededor de la investigación sobre los procesos históricos de las relaciones entre los géneros. ¿Cuándo y cómo empezó la discriminación, la marginalización de las mujeres hacia el lugar de la "otredad"?

Obviamente esta visión tiene como punto de referencia lo masculino, como natural, centro y punto de partida de lo propio. Me parece interesante para pensar sobre el desarrollo histórico que colocó lo femenino en el "afuera", en lo "extraño", siempre también "temido". ¿Cuándo y cómo empezó esta discriminación, opresión, marginalización? En la búsqueda de re-escribir y reinterpretar la historia, escrita por hombres, topamos con la pregunta de ¿cuándo reemplazó el monoteismo patriarcal las diosas y dioses? ¿Qué se entiende como "inicio de la civilización"? Nos olvidamos que solamente muy pocas mujeres fueron alfabetizadas en la Edad Media y apenas existen documentos escritos por mujeres antes del siglo XIX. ¿Cómo ocurrió entonces la exclusión de las mujeres de la educación y del poder público y cómo se instalaron los privilegios de los hombres? ¿Fue un proceso pacífico o fue una lucha manifiesta? Desde los tiempos modernos, como lo indica la profesora Hidalgo, tenemos testimonio de la persecución, los asesinatos y la exclusión de mujeres rebeldes, "diferentes", no sometidas al poder dominante. Por supuesto toda esta lucha tendrá su reflejo en la psíque de ambos géneros. Como lo indican Hidalgo y muchas psicoanalistas, la problemática de los hombres en culturas muy centradas en el dominio intrafamiliar de la madre, suele centrarse en la fuerte dependencia y miedo hacia la madre omnipotente. En los conflictos por lograr su autonomía se manifiesta el odio del varón desde el narcisismo, igual que desde la problemática edípica. El establecimiento de mecanismos de defensa se corresponde con las 
ofertas culturales y puede manifestarse en nuestra cultura como desprecio, negación e incapacidad de soportar la dependencia, hasta la ira narcicista violenta dirigida hacia las mujeres.

\section{Conclusiones}

Sabemos que es justamente el psicoanálisis el que demuestra la necesidad de nombrar las cosas y los hechos claramente para no dejarlas al "destino neurótico". Sin duda el trabajo de Roxana Hidalgo en conjunto con los muchos escritos de psicoanalistas feministas señalan hacia el fenómeno de instalación en el pensamiento psicoanalítico de nuevos mitos, reflejos de viejas ideas patriarcales, "continentes oscuros", no interpretados. Freud admitió que no sabe "que quieren las mujeres", pero a pesar de esta declaración humilde creó despues teorías que pretenden ser verdades sobre la sexualidad femenina. Recordar, repetir y elaborar para tener más libertad interna puede significar más libertad para cambiar la historia, allí significa sufrimiento e injusticia social e individual. Esto es el lema de un psicoanálisis crítico social y comprometido dentro de su ambiente social y cultural. Superar las fantasías, miedos, confusiones, incertidumbres; confrontarse conscientemente con la tendencia de olvidar las experiencias dolorosas o vergonzosas en favor de hablar, expresar, compartir, lo que muchas veces empieza en el ambiente contenedor de la terapia. Esperamos que no se quede ahí, en lo privado del consultorio sino que entre en el ambiente social a través de las palabras de mujeres y hombres que tienen el valor de disentir.

En este sentido felicito -aparte de la profesora Hidalgo- a las/los iniciadores de esta discusión y espero que en el ambiente científico nacional se multipliquen estos esfuerzos tan valiosos y necesarios. En tiempos de autoritarismo, xenofobia y miseria económica en todo el continente latinoamericano es aún más importante llevar al público las reflexiones críticas y no temer al pensamiento rebelde e irreverente. Sabemos que solamente en debates abiertos y críticos puede desarrollarse la fortaleza de argumentar y analizar críticamente nuestro propio quehacer en el específico contexto histórico social y cultural; también conocemos las dificultades que hay que afrontar.

Para concluir quiero agradecer a Roxana Hidalgo su esfuerzo por hacer un puente entre sus estudios en Alemania (e integrar bibliografía en alemán) y Costa Rica con este aporte tan importante. Pienso que más que nunca estos puentes entre el "primer mundo" y el "tercer mundo" son necesarios, porque significan redes de pensar y actuar juntas en tiempos que la competencia y la individualización son promovidas por el sistema dominante, también en el ambiente académicocientífico. Esto fue tambien el objetivo de la maestría en psicoanálisis en la Universidad de Costa Rica, cuando promoví la corriente del etno-psicoanálisis. No siempre se logran las metas, sin duda si nuestro esfuerzo científico sigue la tradición de la/del "intelectual comprometida/o", podemos cruzar fronteras y resistencias externas e internas, para aportar desde nuestro lugar social nuevos conocimientos importantes para una red social, que se entiende como transformadora. Esto ha sido siempre una meta en la búsqueda y la lucha de científicas feministas y psicoanalistas de la corriente crítica-social. 


\section{Referencias} Press.

Butler, J. (2000). Antigone's claim. Kinship between life and death. New York: Stanford University

Carrillo, E. (2000). La lucha interna del psicoanálisis: entre el narcisismo y el narcisismo del analista. Giros de ASPAS, 5, pp. 85-93.

Engels, F. (1880/1979). Der Ursprung der Familie, des Privateigentums und des Staates. En Marx/Engels obras completas, Vol. VT. Berlin.

Fallend, K. (1988). Wilhelm Reich in Wien. Psycho-Analyse und Politik. Salzburg: Geyer.

Fanon, F. (1952). Peau noir, masques blancs. Paris: Seuil.

Hauser, U. (2000, a). El psicodrama psicoanalítico con mujeres salvadoreñas en el contexto de traumatismos de guerra. Giros de ASPAS, 5, pp. 40-54.

Hauser, U. (2000, b). Deconstrucción de la sexualidad, mitos tabúes y estereotipos. Conferencia impartida en la Universidad Nacional, Heredia, Costa Rica.

Hidalgo, R. y Chacón L. (2001). Cuando la feminidad se trastoca en el espejo de la maternidad. San José: Editorial de la Universidad de Costa Rica.

Jacoby, R. (1983). The represion of Psychoanalysis. New York: Basic Books, Inc. Publishers.

Klein, M. (1932/ 1949). The Psychoanalysis of Children. London: Hogarth Press.

Langer, M. (1951). Maternidad y sexo. Estudio psicoanalítico y psicosomático. Buenos Aires: Paidós. Press.

Mahler, M.(1952). The Psychoanalytic Study of the Child. New Zork: International Universites

Modena, E. (2000). Proyecto de un psicoanálisis crítico: algunos pensamientos introductorios. Giros de ASPAS 5, pp. 93-104. Atlantis.

Parin, P.; Parin-Matthey, G.; Morgenthaler, F. (1963). Die Weissen denken zuviel. Zurich:

Reichmayr, J. (1990). Spurensuche in der Geschichte der Psychoanalyse. Frankfurt: Nexus. 